\title{
Polyostotic fibrous dysplasia of the ribs: An unusual cause of chest pain and dyspnea
}

This article was published in the following Dove Press journal:

International Medical Case Reports Journal

29 July 2009

Number of times this article has been viewed

\author{
Sevket Ozkaya' \\ Serhat Findik ${ }^{2}$ \\ Hasan Demir ${ }^{\prime}$ \\ Canan Yuksel ${ }^{3}$ \\ Atilla Guven Atici \\ 'Samsun Chest Disease and Chest \\ Surgery Hospital, Samsun, Turkey; \\ ${ }^{2}$ Ondokuz Mayis University, Faculty \\ of Medicine, Department of Pulmonary \\ Medicine, Samsun, Turkey; ${ }^{3}$ Samsun \\ Pathology and Cytology Centre, \\ Samsun, Turkey
}

\begin{abstract}
Fibrous dysplasia is a benign bony abnormality that may be monostotic or polyostotic and is not included in the differential diagnosis of chest pain and dyspnea, since it is typically asymptomatic. A 36-year-old man presented with left-sided chest pain and dsypnea for three months. Chest X-ray and chest computed tomography scan revealed a large solid mass arising from the anterior parts of the left fourth, fifth, and sixth ribs and compressing the adjacent lung parenchyma. The tumor was completely removed surgically and histopathologic examination was consistent with fibrous dysplasia without malignant transformation. This report demonstrates that polyostotic dysplasia of the ribs may cause chest pain and dyspnea and present radiographically as a large mass.
\end{abstract}

Keywords: chest wall, imaging, computed tomography, thoracotomy

\section{Introduction}

Polyostotic fibrous dysplasia is a rare developmental disorder with focal areas of abnormal bony architecture. We present an exceptional case of a polyostotic fibrous dysplasia of the ribs.

\section{Case report}

A 36-year-old man was admitted to our hospital with complaints of left-sided chest pain and shortness of breath for the previous two weeks. Past history and family history were not significant. Physical examination was within normal limits except tenderness in the left side of the chest at the level of the fourth to sixth ribs. A chest X-ray (Figure 1) and computed tomography (CT) scan of the chest (Figure 2) showed a large thoracic mass arising from the lateral parts of the left fourth to sixth ribs.

Thoracotomy was performed. A frozen section biopsy at the time of surgery was consistent with fibrous dysplasia and thus, the tumor was completely removed with en-block resection with $2 \mathrm{~cm}$ margins. Also, three ribs were sectioned during invasion. The chest wall defect did not require reconstruction with prosthesis. The postoperative course was uneventful with resolution of the symptoms.

The surgical specimen was a hard, lobulated and partially calcified tumor arising from the lateral part of the left fourth to sixth ribs which measured $16 \times 11 \times 6 \mathrm{~cm}$ (Figure 3). The tumor had two components: 1) multiple cysts containing yellowish-serous fluid and 2) creamy solid areas. Cysts were multiple and the largest had a diameter of $9 \mathrm{~cm}$. Microscopically, the tumor had a typical histologic appearance of fibrous dysplasia. Neither cellular atypia, mitotic figures, nor necrosis were observed (Figure 4).
Correspondence: Serhat Findik Associate professor, Ondokuz Mayis University, Faculty of Medicine, Department of Pulmonary Medicine, Kurupelit, TR-55 I39, Samsun, Turkey Tel +905325868869

Email serhatfindikI@yahoo.com 


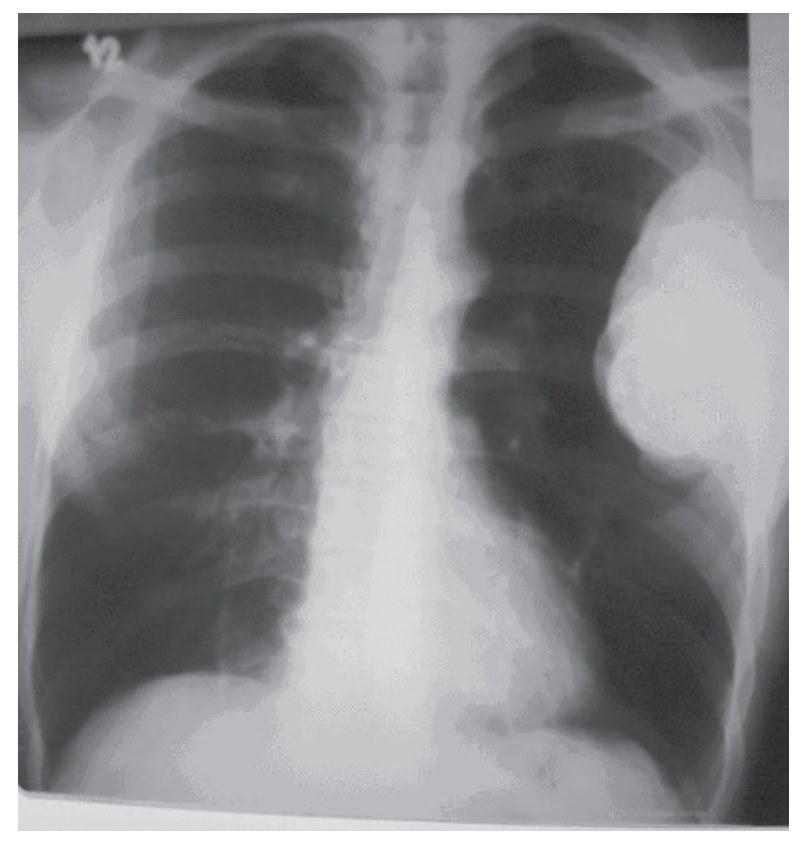

Figure I A chest $\mathrm{X}$-ray demostrates a large peripheral mass arising from the lateral parts of the left fourth to sixth ribs.

\section{Discussion}

Fibrous dysplasia is a sporadic developmental condition affecting bones, which show poor mechanical strength leading to pathologic fractures and progressively enlarging deformities that impinge on adjacent structures. Monostotic involvement occurs more commonly than the polyostotic form. Monostotic disease does not usually progress to polyostotic disease, and the size and number of lesions generally remain the same over time as they were at initial radiologic evaluation. ${ }^{1,2}$ Bony involvement in polyostotic fibrous

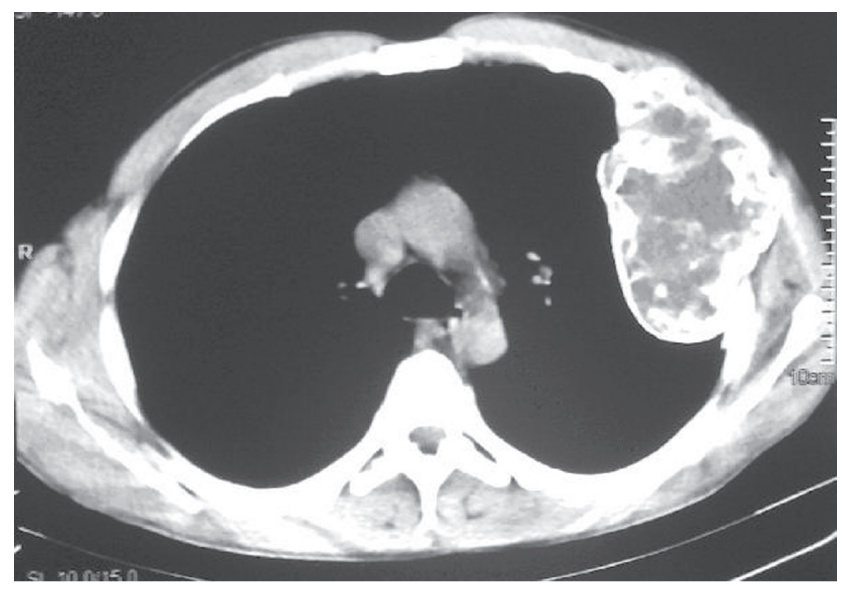

Figure 2 Axial computed tomography (CT) scan at the level of the aortic arch shows an expansile mass with areas of ground-glass attenuation and irregular calcification in left fourth to sixth ribs.

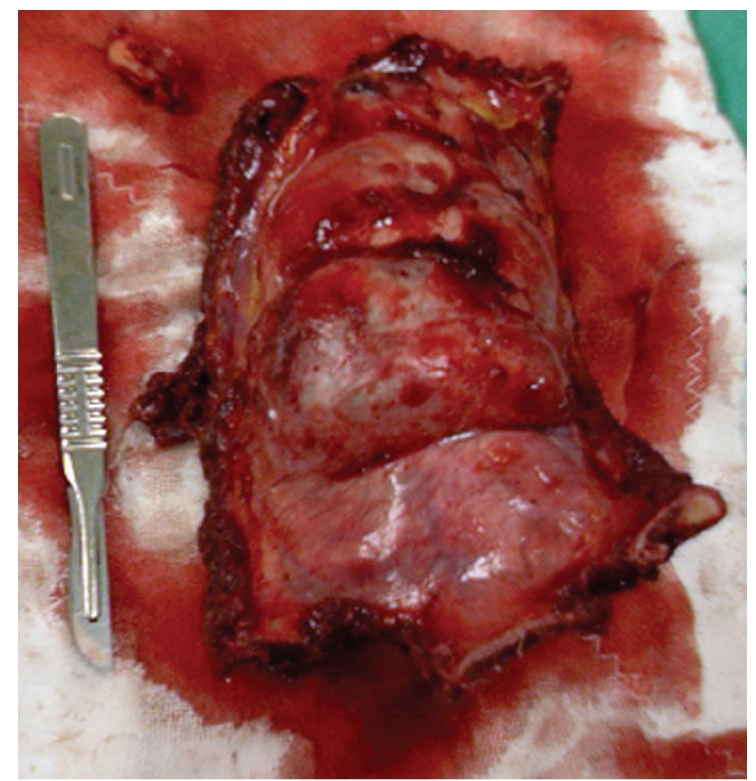

Figure 3 The surgical specimen was a hard, lobulated and partially calcified tumour arising from lateral part of the left fourth to sixth ribs which measured $16 \times 11 \times 6 \mathrm{~cm}$. The tumor had two components: multiple cysts containing yellowish-serous fluid and solid areas.

dysplasia typically includes facial bones, skull base, long bones, and occasionally ribs.

Chest pain, an unusual symptom resulting from polyostotic fibrous dysplasia of the ribs, has been reported previously in only two papers. ${ }^{3,4}$ Rarely, multiple lesions are sufficient to result in progressive restrictive lung disease, pulmonary hypertension, and cor pulmonale..$^{2,5,6}$

Radiographs characteristically show unilateral fusiform enlargement and deformity with cortical thickening and increased trabeculation of one or more ribs. Amorphous or

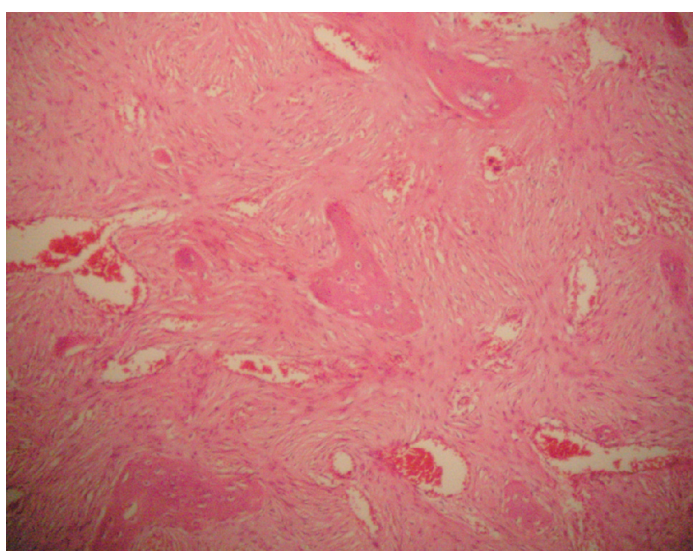

Figure 4 Histological appearance diagnostic of fibrous dysplasia. The mesenchymal stroma surrounding the dysplastic trabeculae is relatively hypocellular. There is a lack of osteoblastic rimming surrounding the dysplastic trabeculae (hematoxylin and eosin stain, $\times 200$ ). 
irregular calcification is often seen on CT sections of the lesion $^{1,2}$ as in our case.

Costal lesions of fibrous dysplasia are also known to develop after the end of growth because of cystic degeneration, with occasional formation of an aneurysmal cyst. ${ }^{7}$ Development of a huge benign costal mass compressing the mediastinum is exceptional. Since this complication is rare, a prophylactic resection for small fibrous dysplasia is probably not justified. Even when the tumor is massive, as in our case, surgical resection is still possible since fibrous dysplasia of bone is a benign and noninfiltrative tumor. It must be kept in mind that malignancy occurs in less than $1 \%$ of cases of fibrous dysplasia. ${ }^{8}$ Thus, surgical approach is usually only performed for exact diagnosis. ${ }^{9}$

In conclusion, polyostotic fibrous dysplasia of the ribs, although it is rare, may be included in differential diagnosis of chest pain.

\section{Disclosures}

The authors report no conflicts of interest in this work.

\section{References}

1. Tateishi U, Gladish GW, Kusumoto M, et al. Chest wall tumors: radiologic findings and pathologic correlation: part 1. Benign tumors. Radiographics. 2003;23:1477-1490.

2. DiCaprio MR, Enneking WF. Fibrous dysplasia. Pathopyhsiology, evaluation, and treatment. J Bone Joint Surg Am. 2005;87:1848-1864.

3. Ayadi-Kaddour A, Ben Slama S, Marghli A, et al. [Fibrous dysplasia of the rib. Ten case reports.] Rev Chir Orthop Reparatrice Appar Mot. 2008;94:301-307.

4. Sethi RS, Climie ARW, Tuttle WM. Fibrous dysplasia of the rib with sarcomatous change. J Bone Joint Surg Am. 1962;44:183-188.

5. King RM, Payne WS, Olafsson S, Unni KK. Surgical palliation of respiratory insufficiency secondary to massive exuberant polyostotic fibrous dysplasia of the ribs. Ann Thorac Surg. 1985;39: 185-187.

6. Gutierrez G, Suskin M. Polyostotic fibrous dysplasia of the ribs causing severe restrictive lung disease with acute on chronic respiratory failure. Chest Meeting Abstracts. 2004;126:937S-938S.

7. de Montpreville VT, Dulmet E, Ponlot R, Dartevelle P. Giant bilateral fibrous dysplasia of first ribs: compression of mediastinum and thoracic outlet. Eur Respir J. 1995;8:1028-1029.

8. Ruggieri P, Sim FH, Bond JR, Unni KK. Malignancies in fibrous dysplasia. Cancer. 1994;73:1411-1424.

9. Cavanaugh DG, Cabellon S, Peake JB. A logical approach to chest wall neoplasms. Ann Thorac Surg. 1986;41:436-437.
International Medical Case Reports Journal

\section{Publish your work in this journal}

The International Medical Case Reports Journal is an international, peer-reviewed open-access journal publishing original case reports from all medical specialties. Previously unpublished medical posters are also accepted relating to any area of clinical or preclinical science. Submissions should not normally exceed 2,000 words or

\section{Dovepress}

4 published pages including figures, diagrams and references. The manuscript management system is completely online and includes a very quick and fair peer-review system, which is all easy to use. Visit http://www.dovepress.com/testimonials.php to read real quotes from published authors. 